\title{
ANALYSIS OF TOOL WEAR AND SURFACE ROUGHNESS IN HIGH-SPEED MILLING PROCESS OF ALUMINUM ALLOY AL6061
}

\author{
Nhu-Tung Nguyen \\ HaUI Institute of Technology - HIT ${ }^{l}$ \\ tungnn@haui.edu.vn \\ Dung Hoang Tien \\ Faculty of Mechanical Engineering ${ }^{l}$ \\ tiendung@haui.edu.vn \\ Nguyen Tien Tung \\ Faculty of Mechanical Engineering ${ }^{l}$ \\ nguyentientung@haui.edu.vn \\ Nguyen Duc Luan \\ HaUI Institute of Technology-HIT \\ nguyenducluan@haui.edu.vn \\ ${ }^{1}$ Hanoi University of Industry \\ 298 Cau Dien str., Bac Tu Liem District, Hanoi, Vietnam, 100000
}

Abstract

In this study, the influence of cutting parameters and machining time on the tool wear and surface roughness was investigated in high-speed milling process of Al6061 using face carbide inserts. Taguchi experimental matrix $\left(L_{9}\right)$ was chosen to design and conduct the experimental research with three input parameters (feed rate, cutting speed, and axial depth of cut). Tool wear $(V B)$ and surface roughness $(R a)$ after different machining strokes (after 10, 30, and 50 machining strokes) were selected as the output parameters. In almost cases of high-speed face milling process, the most significant factor that influenced on the tool wear was cutting speed (84.94\% after 10 machining strokes, $52.13 \%$ after 30 machining strokes, and $68.58 \%$ after 50 machining strokes), and the most significant factors that influenced on the surface roughness were depth of cut and feed rate $(70.54 \%$ after 10 machining strokes, $43.28 \%$ after 30 machining strokes, and $30.97 \%$ after 50 machining strokes for depth of cut. And $22.01 \%$ after 10 machining strokes, $44.39 \%$ after 30 machining strokes, and $66.58 \%$ after 50 machining strokes for feed rate). Linear regression was the most suitable regression of $V B$ and $R a$ with the determination coefficients $\left(R^{2}\right)$ from $88.00 \%$ to $91.99 \%$ for $V B$, and from $90.24 \%$ to $96.84 \%$ for $R a$. These regression models were successfully verified by comparison between predicted and measured results of $V B$ and $R a$. Besides, the relationship of $V B, R a$, and different machining strokes was also investigated and evaluated. Tool wear, surface roughness models, and their relationship that were found in this study can be used to improve the surface quality and reduce the tool wear in the high-speed face milling of aluminum alloy Al6061.

Keywords: High-speed, Too Wear, Surface Roughness, Face Milling, Machining Process, Aluminum Alloy, Al6061, ANOVA, Taguchi.

DOI: $10.21303 / 2461-4262.2021 .001824$

\section{Introduction}

Milling is not only a common machining process, but also one of the most used in computer numerical control (CNC) machines. Tool wear, machining surface roughness, etc. are very important characteristics, and are often selected as the parameters that characterize for the quality and efficiency of the milling process.

Up to now, many studies were performed to evaluate the effect of technological parameters and cutting conditions on the tool wear and machining surface roughness to improve the quality 
and reduce the cost and time of machining processes. These studies were performed with the normal cutting conditions and with different machining methods such as grinding [1], drilling [2], turning [3-6], milling [7-10], and so on. In machining processes, the tool wear and surface roughness in these were investigated and modeled following two directions that were theoretical modelling and experimental modelling.

In the theoretical modelling method, the tool wear and surface roughness were modeled by theoretical method depending on the physical, chemical, and geometrical phenomena such as friction, temperature, cutting, etc. $[11,12]$. This approach is often quite difficult to perform because too many factors that should be considered to add into the tool wear and surface roughness models $[13,14]$. In the second direction, the tool wear and surface roughness were modeled depending on the experimental data. This approach can be applied for specific cases in which only several factors were considered in the investigation of their influence on the tool wear and surface roughness [7-9]. Therefore, many studies focused on experimental modeling methods with a limited amount of input parameters [15-19]. In the experimental modelling method, many approaches were applied to model the tool wear and surface roughness. In which, several studies were performed to model the tool wear and surface roughness based on the cutting time or the number of machining strokes. The results from these studies showed that depending on the machining time or the number of machining strokes, the tool wear and surface roughness also changed $[16,17,20]$.

The tool wear and surface roughness were investigated in milling process depending on the cutting time. This study was carried out to verify the change in surface roughness of the workpiece due to increasing tool wear [10]. The neural approach was conducted to investigate the effect of cutting condition of tool wear and surface roughness in turning process under minimum quantity lubrication (MQL) environment [11]. The response surface method was applied to analyze the effect of the technological parameters on the tool wear and surface roughness. Besides, using this method, the tool wear and surface roughness were also modeled [15-19]. Taguchi method was used to design the experimental matrix, to investigate the influence of technological parameters and cutting conditions on the tool wear and surface roughness. Besides, this method was also used to obtain the optimum cutting parameters to improve the surface quality and tool life. These studies were often conducted in a CNC machine with the different cutting tool and workpiece material [21-23].

Aluminum alloy is a common material. With many outstanding advantages such as: Good elasticity, light weight, easy to work, and so on. Therefore, aluminum alloy is often used a lot in the machinery manufacturing, automobile manufacturing technology, mold technology, aviation, space, architecture, etc. [24]. With traditional machining processes, aluminum alloy materials are often used within conventional cutting conditions [19-24]. So, the quality and efficiency of the machining process are not really good. Studies show that, for a machine or a machining center, the tool wear and surface roughness are highly dependent on the technological parameters. In particular, the studies have shown that high-speed milling can provide surface quality with a gloss equivalent to grinding, surface polishing time after high-speed milling is much smaller than traditional machining method. At the same time, the material removal capacity is also much higher than that one of traditional machining methods [25]. Therefore, the research to apply high-speed milling to machining aluminum alloys is a suitable direction to improve the quality and efficiency of the machining process.

This study was conducted to evaluate the influence of milling parameters and the number of machining strokes on the tool wear and surface roughness in high-speed face milling of the aluminum alloy A16061. By analyzing the experimental results, the effect of cutting conditions on the tool wear and surface roughness was evaluated. Besides, the relationship between tool wear, surface roughness, and number of machining strokes was also investigated.

\section{Materials and methods}

\section{1. The setup of experimental method}

The experiments were conducted using the face mill tool with two carbide inserts. The cutter diameter was $20 \mathrm{~mm}$. The length of tool shank was $150 \mathrm{~mm}$ with sign 300R C20-20-150 $2 \mathrm{~T}$. Tool and inserts was described as in Fig. 1. The parallelogram insert (APMT1135PDER-M2 VP15TF, Japan) that has two cutting noses. The radius of the insert nose $r=0.8 \mathrm{~mm}$. 


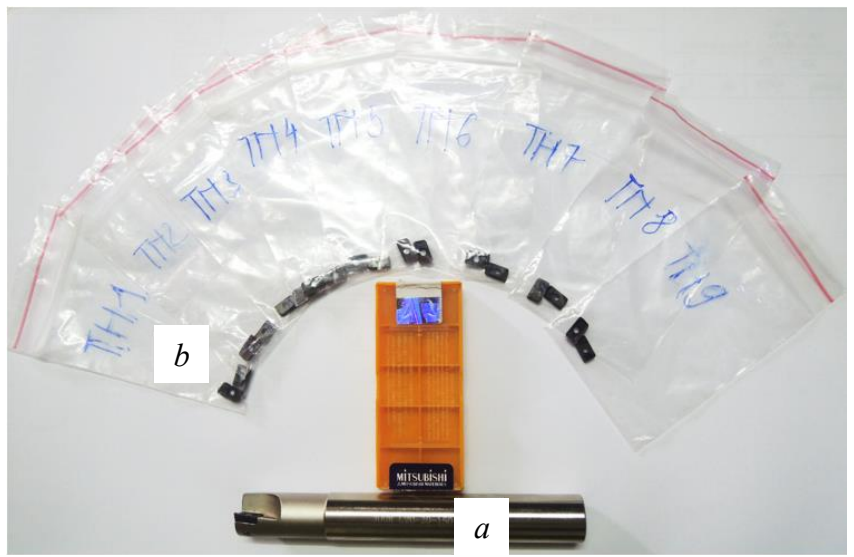

Fig. 1. Experimental tool shank and inserts: $a$ - Tool shank; $b$ - Inserts

The workpiece material was aluminum alloy Al6061 with the chemical compositions as listed in Table 1 and properties as listed in Table 2.

Table 1

Chemical compositions of A16061

\begin{tabular}{cccccccccc}
\hline Element & Al & $\mathbf{C r}$ & $\mathbf{C u}$ & $\mathbf{F e}$ & $\mathbf{M g}$ & $\mathbf{M n}$ & $\mathbf{S i}$ & $\mathbf{T i}$ & $\mathbf{Z n}$ \\
\hline$\%$ & 98 & $\leq 0.3$ & $\leq 0.4$ & $\leq 0.7$ & $\leq 1.2$ & $\leq 0.15$ & $\leq 0.8$ & $\leq 0.15$ & $\leq 0.25$
\end{tabular}

Table 2

Properties of aluminum alloy A16061

\begin{tabular}{ccc}
\hline Quantity & Value & Unit \\
\hline Hardness & Mechanical Properties & $\mathrm{HB}$ \\
Young's modulus & 95 & $\mathrm{GPa}$ \\
Ultimate Tensile strength & 68.9 & $\mathrm{MPa}$ \\
Elongation & 310 & $\%$ \\
Fatigue strength & $12-17$ & $\mathrm{MPa}$
\end{tabular}

\begin{tabular}{ccc}
\hline & Physical Properties & \\
\hline Thermal conductivity & 167 & $\mathrm{~W} / \mathrm{m} . \mathrm{K}$ \\
Specific heat & 0.896 & $\mathrm{~J} / \mathrm{g} \cdot \mathrm{K}$ \\
Melting temperature & 660 & ${ }^{\circ} \mathrm{C}$ \\
Density & 2.7 & $\mathrm{~g} / \mathrm{cm}^{3}$ \\
Resistivity & 0.399 & $\mathrm{Ohm} \cdot \mathrm{mm}^{2} / \mathrm{m}$
\end{tabular}

The dimensions of workpiece were the length of $150 \mathrm{~mm}$, the width of $15 \mathrm{~mm}$, and the height of $150 \mathrm{~mm}$ as shown in Fig. 2.

A five-axis vertical machining center (DMU 50 - 5 Axis Milling) was used to conduct the experiments as described in Fig. 3. The maximum spindle speed is 14,000 rpm, the power of spindle speed is $14.5 \mathrm{~kW}$, the maximum feedrate is $30,000 \mathrm{~mm} / \mathrm{min}$, and the travel $X / Y / Z$ are $500 / 450 / 400 \mathrm{~mm}$. The experiments were performed under overflow irrigation lubrication condition using Ultra cut FX 6090 fluid. 


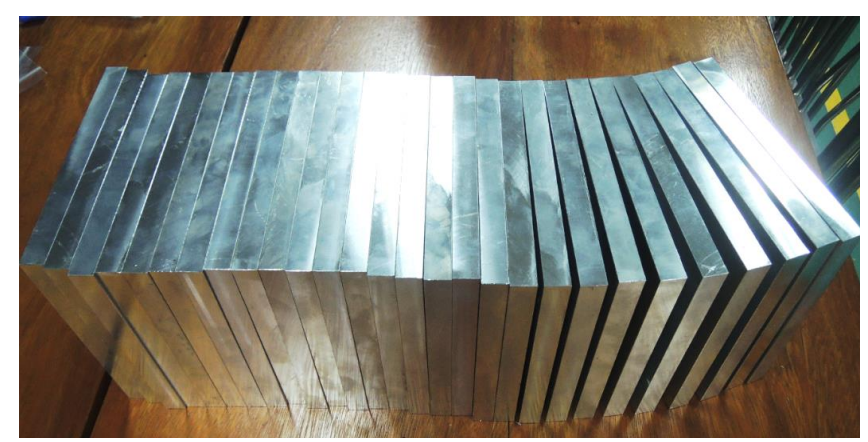

Fig. 2. Experimental workpieces

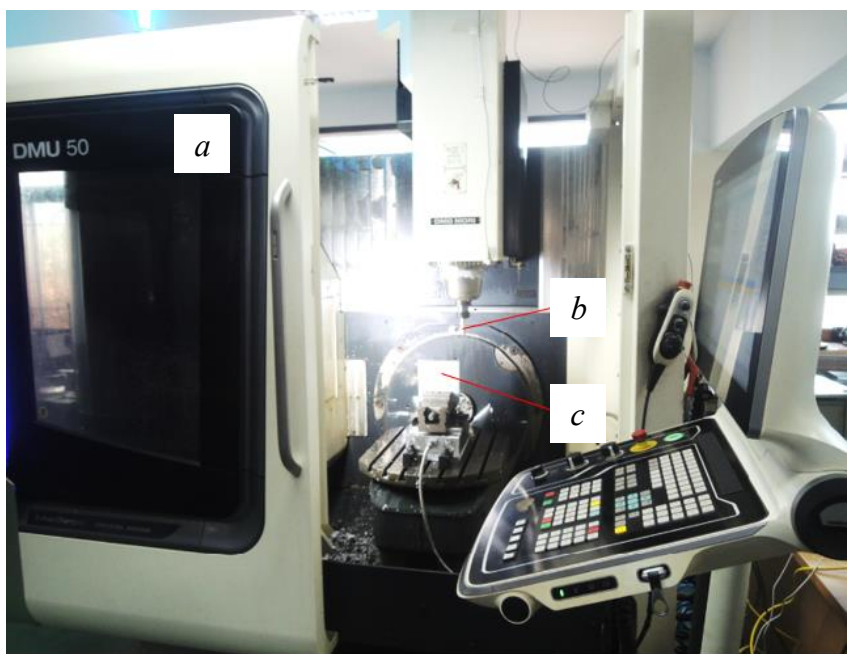

Fig. 3. Experimental machine: $a-\mathrm{CNC}$ machine; $b$-Tool; $c$ - Workpiece

In this study, the flank wear (VB) was used to analyse the influence of cutting parameter on tool wear. The flank wear of tool of the product was measured by LEICA DM750 M Microscope system as described in Fig. 4.

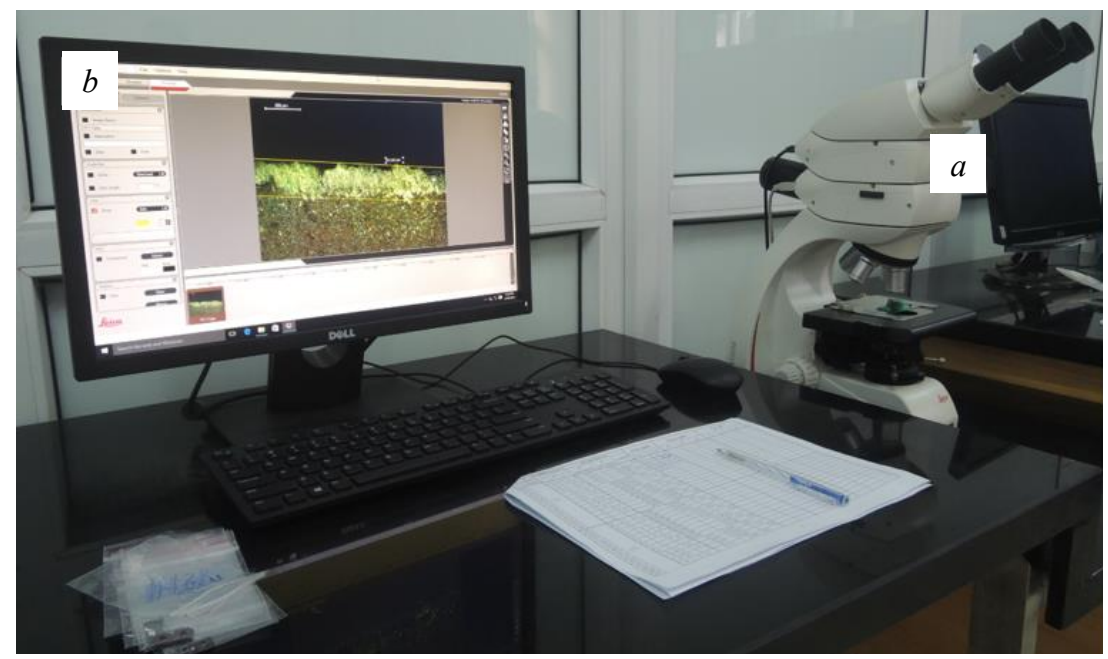

Fig. 4. Tool wear measurement system: $a$ - Microscope; $b$ - Processing system

The magnification of the measuring system is $50 \times, 100 \times, 200 \times$ and $500 \times($ Objective $5 \times, 10 \times$, $20 \times$ and $50 \times$ - Eyepiece: $10 \times$ ). The software used for the analysis is LAS EZ software. The tool wear values were measured after three machining strokes (after 10 strokes, after 50 strokes, and 
after 50 strokes). For each experiment, the tool wear was measured for two inserts of each cutting, the average value of tool wear of two inserts was stored to evaluate the results of tool wear. Tool wear and machining surface roughness are measured after different number of machining strokes. The smallest number of machining strokes is determined based on initial experiments (probe experiments). probe experiments have shown that within 10 machining strokes, the tool wear can be determined quite clearly on the microscopes that was used to measure wear. Therefore, this study selected the number of strokes to perform the tool wear and surface roughness measurements of 10,30 , and 50 strokes.

The surface roughness is measured with the MITUTOYO-Surftest SJ-210 Portable Surface Roughness Tester (Japan) as shown in Fig. 5. SurfTest SJ USB Communication Tool Ver5.007 software allows display and storage Measured parameters $R a, R z, R q$ are in accordance with ISO 1997 standard. The standard measuring range is $4 \mathrm{~mm}$.

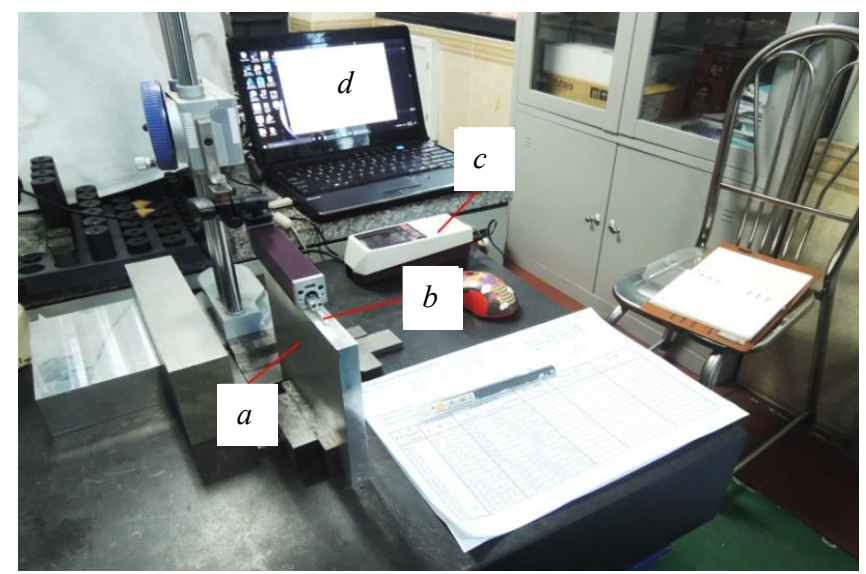

Fig. 5. Surface roughness measurement system: $a$-Workpiece; $b$ - Surface roughness sensor; $c$-Data processing; $d$ - PC and software

The machining surface roughness is measured parallel to the toolpath. Each experiment was measured 3 times, the average value of 3 times was used to analyze and evaluate experimental results.

\section{2. Design of Experimental Matrix}

Based on the recommended of the manufacturing about the machining ability of the tool, based on the maximum capacity of the experimental CNC machine, and based on the maximum value of cutting speed for aluminum alloy A16061 material using a carbide face milling cutter with two inserts and diameter of $20 \mathrm{~mm}$, the input cutting parameters and their levels were chosen at high-speed conditions and listed in Table 3.

Table 3

Control factors and their levels

\begin{tabular}{ccccc}
\hline No. & Control factors & Level 1 & Level 2 & Level 3 \\
\hline 1 & Feed rate, fz (mm/flute) & 0.100 & 0.125 & 0.150 \\
2 & Cutting speed, V (m/min) & 650 & 750 & 850 \\
3 & Axial depth of cut, a (mm) & 0.2 & 0.4 & 0.6
\end{tabular}

In this study, with three controllable cutting parameters including feed rate $(f z)$, cutting speed $(V)$, and axial depth of cut $(a)$, the Taguchi experimental method and variance analysis (ANOVA) method has been applied to construct the experimental matrix and evaluate the experimental results. The experimental matrix according to Taguchi method was designed and listed in Table 4. 
Table 4

The experimental design and results

\begin{tabular}{|c|c|c|c|c|c|c|c|c|}
\hline \multirow{2}{*}{ No. } & \multicolumn{3}{|c|}{ Coded factors } & \multicolumn{3}{|c|}{ Actual factors } & \multirow{2}{*}{$\frac{V b}{(\mu \mathrm{m})}$} & \multirow{2}{*}{$\begin{array}{c}\text { Ra } \\
(\mu \mathrm{m})\end{array}$} \\
\hline & $A$ & $B$ & $C$ & $f z$ & $V$ & $a$ & & \\
\hline \multicolumn{9}{|c|}{10 strokes machining } \\
\hline 1 & -1 & -1 & -1 & 0.1 & 650 & 0.2 & 138.015 & 0.422 \\
\hline 2 & -1 & 0 & 0 & 0.1 & 750 & 0.4 & 141.090 & 0.364 \\
\hline 3 & -1 & 1 & 1 & 0.1 & 850 & 0.6 & 144.755 & 0.259 \\
\hline 4 & 0 & -1 & 0 & 0.125 & 650 & 0.4 & 136.735 & 0.330 \\
\hline 5 & 0 & 0 & 1 & 0.125 & 750 & 0.6 & 143.330 & 0.282 \\
\hline 6 & 0 & 1 & -1 & 0.125 & 850 & 0.2 & 147.670 & 0.508 \\
\hline 7 & 1 & -1 & 1 & 0.15 & 650 & 0.6 & 135.745 & 0.329 \\
\hline 8 & 1 & 0 & -1 & 0.15 & 750 & 0.2 & 138.350 & 0.545 \\
\hline 9 & 1 & 1 & 0 & 0.15 & 850 & 0.4 & 144.765 & 0.494 \\
\hline \multicolumn{9}{|c|}{30 strokes machining } \\
\hline 1 & -1 & -1 & -1 & 0.1 & 650 & 0.2 & 158.990 & 0.410 \\
\hline 2 & -1 & 0 & 0 & 0.1 & 750 & 0.4 & 163.010 & 0.394 \\
\hline 3 & -1 & 1 & 1 & 0.1 & 850 & 0.6 & 166.390 & 0.360 \\
\hline 4 & 0 & -1 & 0 & 0.125 & 650 & 0.4 & 145.420 & 0.436 \\
\hline 5 & 0 & 0 & 1 & 0.125 & 750 & 0.6 & 158.570 & 0.352 \\
\hline 6 & 0 & 1 & -1 & 0.125 & 850 & 0.2 & 165.785 & 0.564 \\
\hline 7 & 1 & -1 & 1 & 0.15 & 650 & 0.6 & 145.085 & 0.426 \\
\hline 8 & 1 & 0 & -1 & 0.15 & 750 & 0.2 & 147.865 & 0.620 \\
\hline 9 & 1 & 1 & 0 & 0.15 & 850 & 0.4 & 159.665 & 0.580 \\
\hline \multicolumn{9}{|c|}{50 strokes machining } \\
\hline 1 & -1 & -1 & -1 & 0.1 & 650 & 0.2 & 182.635 & 0.382 \\
\hline 2 & -1 & 0 & 0 & 0.1 & 750 & 0.4 & 191.125 & 0.334 \\
\hline 3 & -1 & 1 & 1 & 0.1 & 850 & 0.6 & 197.140 & 0.294 \\
\hline 4 & 0 & -1 & 0 & 0.125 & 650 & 0.4 & 168.230 & 0.431 \\
\hline 5 & 0 & 0 & 1 & 0.125 & 750 & 0.6 & 178.695 & 0.409 \\
\hline 6 & 0 & 1 & -1 & 0.125 & 850 & 0.2 & 197.465 & 0.532 \\
\hline 7 & 1 & -1 & 1 & 0.15 & 650 & 0.6 & 170.860 & 0.424 \\
\hline 8 & 1 & 0 & -1 & 0.15 & 750 & 0.2 & 178.710 & 0.527 \\
\hline 9 & 1 & 1 & 0 & 0.15 & 850 & 0.4 & 187.730 & 0.490 \\
\hline
\end{tabular}

The output parameters that were chosen in this study were flank tool wear and surface roughness after three machining strokes (10, 30, and 50 strokes). The minimum strokes that were selected to measure the output parameters were 10 strokes because depending on the trial cutting, after 10 strokes of the milling process, the tool wear can be detected quite clearly by the measurement system.

\section{Experimental Results}

\section{1. Analysis of Tool Wear in high-speed face milling}

The measured results of tool wear after some machining strokes (10 strokes, 30 strokes, and 50 strokes) were listed in Table 4. Analysis results of variance of tool wear after 10 machining strokes, 30 machining strokes, and 50 machining strokes were listed in Table 5.

The ANOVA results that were used to evaluate the effect of cutting parameters on the tool wear and surface roughness with $95 \%$ confidence level and $5 \%$ significance level. The analysis results in these tables show that: During the machining processing of aluminum alloy Al6061 with the carbide cutting insert, after different machining strokes (10 strokes, 30 strokes, and 50 strokes), the parameter that has most influence on the tool wear was the cutting speed (from $52.18 \%$, 
to $84.94 \%$ ). The parameter that has the second influence degree on the tool wear was the feed rate (from $9.73 \%$ to $37.18 \%$ ). The depth of cut has negligible effect on the tool wear (less than $5 \%$ ).

Table 5

ANOVA results for tool wear

\begin{tabular}{|c|c|c|c|c|c|c|}
\hline \multicolumn{7}{|c|}{ ANOVA for tool wear after 10 strokes machining } \\
\hline \multicolumn{3}{|c|}{ Number of obs: 9} & \multicolumn{4}{|c|}{$R$-squared: 0.9494} \\
\hline \multicolumn{3}{|c|}{ Root MSE: 1.88047} & \multicolumn{4}{|c|}{ Adj $R$-squared: 0.7975} \\
\hline Source & Sum of squares & Degree of freedom & Mean square & $F$-value & $\operatorname{Prob}>F$ & Percent contribution (\%) \\
\hline Model & 132.6316 & 6 & 22.1053 & 6.25 & 0.1443 & \\
\hline$f z(\mathrm{~mm} /$ flute $)$ & 13.6316 & 2 & 6.8158 & 1.87 & 0.3489 & 9.73 \\
\hline$V(\mathrm{~m} / \mathrm{min})$ & 119.0262 & 2 & 59.5131 & 16.83 & 0.0561 & 84.94 \\
\hline$a(\mathrm{~mm})$ & 0.4075 & 2 & 0.2038 & 0.06 & 0.9455 & 0.29 \\
\hline Error & 7.0723 & 2 & 3.5362 & - & - & 5.05 \\
\hline Total & 140.1376 & 8 & 17.5172 & - & - & 100.00 \\
\hline \multicolumn{7}{|c|}{ ANOVA for tool wear after 30 strokes machining } \\
\hline \multicolumn{3}{|c|}{ Number of obs: 9} & \multicolumn{4}{|c|}{$R$-squared: 0.8991} \\
\hline \multicolumn{3}{|c|}{ Root MSE: 5.37987} & \multicolumn{4}{|c|}{ Adj $R$-squared: 0.5966} \\
\hline Source & Sum of squares & Degree of freedom & Mean square & $F$-value & Prob $>F$ & Percent contribution $(\%)$ \\
\hline Model & 516.0737 & 6 & 86.0123 & 2.97 & 0.2731 & \\
\hline$f z(\mathrm{~mm} /$ flute $)$ & 213.4260 & 2 & 106.7130 & 3.69 & 0.2134 & 37.18 \\
\hline$V(\mathrm{~m} / \mathrm{min})$ & 299.1818 & 2 & 149.5909 & 5.17 & 0.1621 & 52.13 \\
\hline$a(\mathrm{~mm})$ & 3.4660 & 2 & 1.7330 & 0.06 & 0.9435 & 0.60 \\
\hline Error & 57.8860 & 2 & 28.9430 & - & - & 10.09 \\
\hline Total & 573.9598 & 8 & 71.7450 & - & - & 100.00 \\
\hline \multicolumn{7}{|c|}{ ANOVA for tool wear after 50 strokes machining } \\
\hline \multicolumn{3}{|c|}{ Number of obs: 9} & \multicolumn{4}{|c|}{$R$-squared: 0.9543} \\
\hline \multicolumn{3}{|c|}{ Root MSE: 4.5276} & \multicolumn{4}{|c|}{ Adj $R$-squared: 0.8171} \\
\hline Source & Sum of squares & Degree of freedom & Mean square & $F$-value & Prob $>F$ & Percent contribution (\%) \\
\hline Model & 855.6962 & 6 & 142.6160 & 6.96 & 0.1310 & \\
\hline$f z$ (mm/flute) & 209.1119 & 2 & 104.5560 & 5.10 & 0.1639 & 23.32 \\
\hline$V(\mathrm{~m} / \mathrm{min})$ & 614.9842 & 2 & 307.4921 & 15.00 & 0.0625 & 68.58 \\
\hline$a(\mathrm{~mm})$ & 31.6001 & 2 & 15.8001 & 0.07 & 0.5647 & 3.52 \\
\hline Error & 40.9988 & 2 & 20.4994 & - & - & 4.57 \\
\hline Total & 896.6950 & 8 & 112.0869 & - & - & 100.00 \\
\hline
\end{tabular}

In addition, the influence of each input parameter on the tool wear was shown in Fig. 6, $\boldsymbol{a}-\boldsymbol{c}$, the results from this figure showed that the cutting speed was also the parameter that has most effect on the tool wear. The influence degree of the parameters on the tool wear also varied with the number of machining strokes.

Fig. 6 described the tendency of the influence degree of input parameters on the tool wear based on the number of machining strokes. Following the increasing direction of the number of machining strokes (as the increasing direction of the machining time), the influence of the cutting speed remained the greatest, initially, the influence of the cutting speed on the tool wear decreased. However, after that, the influence of this parameter on tool wear increased. For the parameter that has the second degree of influence on tool wear (feed rate), with the number of machining strokes, initially, the influence of the feed rate on the tool wear increased, but then this influence decreased gradually. According to the number of machining strokes, the depth of cut was also a parameter that has a negligible effect on the tool wear, however, the influence degree this parameter on the tool wear increased with the increasing of number of machining strokes. 


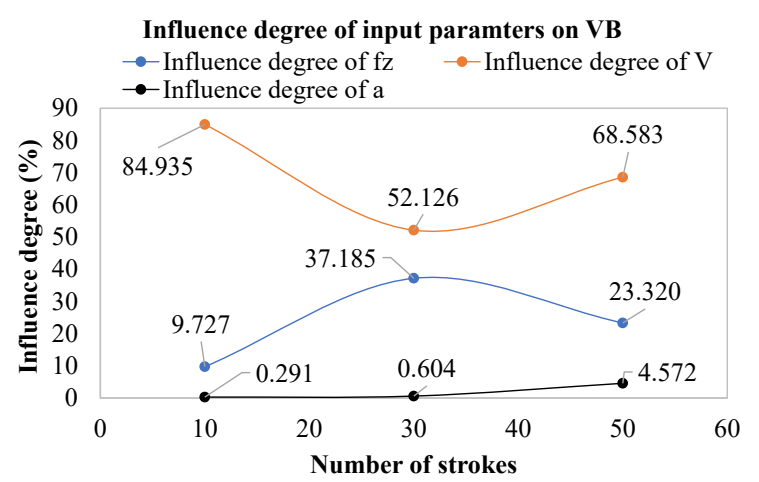

Fig. 6. Effect of cutting parameters on tool wear

Experimental data were used to construct tool wear regression model. Construction results of the regression model are described by (1)-(3). The analysis results showed that the most suitable regression model for tool wear in the case of high-speed face milling of the aluminum alloy Al6061 with the cutting insert was a linear model. Tool wear was model as a first order polynomial of the cutting parameters including the feed rate, the cutting speed, and the axial depth of cut. These regression models were analysed and built with high determination coefficients $R^{2}$. Most of the models have $R^{2}>88 \%$.

The tool wear model after 10 machining strokes was presented by (1):

$$
\left\{\begin{array}{l}
V B(10 \text { strokes })=112.3+33.4 \cdot f z+0.0445 \cdot V-0.17 \cdot a \\
R^{2}=88.00 \%, R_{A j d}^{2}=80.81 \% .
\end{array}\right.
$$

The tool wear model after 30 machining strokes was presented by (2):

$$
\left\{\begin{array}{l}
V B(30 \text { strokes })=134.5+238.5 \cdot f z+0.0706 \cdot V-2.16 \cdot a, \\
R^{2}=89.43 \%, R_{A j d}^{2}=83.08 \%
\end{array}\right.
$$

The tool wear model after 50 machining strokes was presented by (3):

$$
\left\{\begin{array}{l}
V B(50 \text { strokes })=139.9+224.0 \cdot f z+0.101 \cdot V-10.10 \cdot a \\
R^{2}=91.99 \%, R_{A j d}^{2}=87.19 \%
\end{array}\right.
$$

The tool wear model was also successfully verified by comparison of predicted and measured results of tool wear as described in Fig. 7.

The compared results from these figures showed that in all cases with different number of machining strokes, the predicted tool wear was quite close to the measured tool wear. It can be concluded that the linear regression model can be used to model the tool wear in high-speed face milling processes of aluminum alloy A16061.

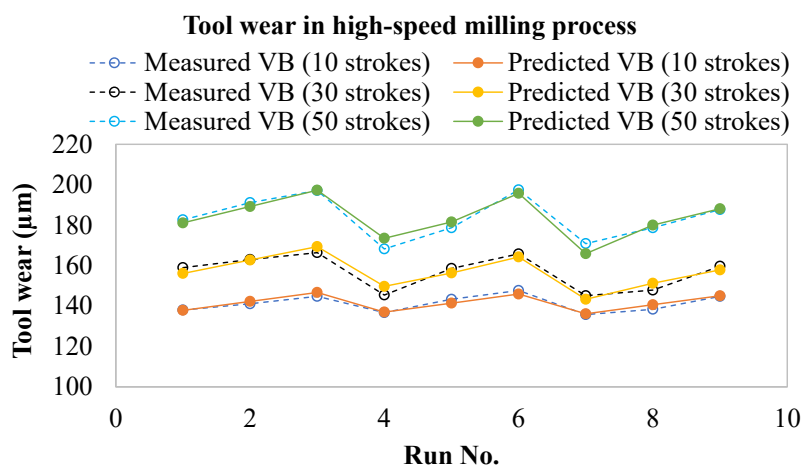

Fig. 7. Comparison of predicted and measured tool wear 


\section{2. Analysis of Surface Roughness in high-speed face milling}

The measured results of surface roughness after some machining strokes (10 strokes, 30 strokes, and 50 strokes) were listed in Table 4. Analysis results of variance of surface roughness after 10 machining strokes, 30 machining strokes, and 50 machining strokes were listed in Table 6.

The analysis results in these tables show that: during the machining processing of aluminum alloy Al6061 with the carbide cutting insert, after different machining strokes (10 strokes, 30 strokes, and 50 strokes), the feed rate and depth of cut were the most influence factors on the surface roughness (from $22.01 \%$, up to $66.58 \%$ for feed rate and from $70.54 \%$ down to $30.97 \%$ for depth of cut) as shown in Fig. 8. The cutting speed has negligible effect on the surface roughness (less than $11.20 \%$ ). Fig. 8 described the tendency of the influence degree of input parameters on the surface roughness based on the number of machining strokes.

The influence degree of the parameters on the surface roughness also varied with the number of machining strokes. Following the increasing direction of the number of machining strokes (As the increasing direction of the machining time), the influence of the feed rate increased, however, the influence of depth of cut on the surface roughness decreased. For the parameter that has negligible effect on the surface roughness (cutting speed), with the number of machining strokes, initially, the influence of the cutting speed on the surface roughness increased.

Table 6

ANOVA results for surface roughness

\begin{tabular}{|c|c|c|c|c|c|c|}
\hline \multicolumn{7}{|c|}{ ANOVA for surface roughness after 10 strokes machining } \\
\hline \multicolumn{3}{|c|}{ Number of obs: 9} & \multicolumn{4}{|c|}{$R$-squared: 0.989} \\
\hline \multicolumn{3}{|c|}{ Root MSE: 0.02185} & \multicolumn{4}{|c|}{ Adj $R$-squared: 0.9559} \\
\hline Source & Sum of squares & Degree of freedom & Mean square & $F$-value & Prob $>F$ & Percent contribution (\%) \\
\hline Model & 0.085597 & 6 & 0.014266 & 29.88 & 0.0327 & \\
\hline$f z(\mathrm{~mm} /$ flute $)$ & 0.019051 & 2 & 0.009526 & 19.95 & 0.0477 & 22.01 \\
\hline$V(\mathrm{~m} / \mathrm{min})$ & 0.005489 & 2 & 0.002744 & 5.75 & 0.1482 & 6.34 \\
\hline$a(\mathrm{~mm})$ & 0.061058 & 2 & 0.030529 & 63.94 & 0.0154 & 70.54 \\
\hline Error & 0.000955 & 2 & 0.000477 & - & - & 1.10 \\
\hline Total & 0.086552 & 8 & 0.010819 & - & - & 100.00 \\
\hline
\end{tabular}

ANOVA for surface roughness after 30 strokes machining

\begin{tabular}{|c|c|c|c|c|c|c|}
\hline \multicolumn{3}{|c|}{ Number of obs: 9} & \multicolumn{4}{|c|}{$R$-squared: 0.9887} \\
\hline \multicolumn{3}{|c|}{ Root MSE: 0.021427} & \multicolumn{4}{|c|}{ Adj $R$-squared: 0.9547} \\
\hline Source & Sum of squares & Degree of freedom & Mean square & $F$-value & Prob $>F$ & Percent contribution $(\%)$ \\
\hline Model & 0.080149 & 6 & 0.013358 & 29.10 & 0.0336 & \\
\hline$f z(\mathrm{~mm} /$ flute $)$ & 0.035985 & 2 & 0.017993 & 39.19 & 0.0249 & 44.39 \\
\hline$V(\mathrm{~m} / \mathrm{min})$ & 0.009078 & 2 & 0.004539 & 9.90 & 0.0919 & 11.20 \\
\hline$a(\mathrm{~mm})$ & 0.035086 & 2 & 0.017543 & 38.21 & 0.0255 & 43.28 \\
\hline Error & 0.000918 & 2 & 0.000459 & - & - & 1.13 \\
\hline Total & 0.081067 & 8 & 0.010133 & - & - & 100.00 \\
\hline
\end{tabular}

ANOVA for surface roughness after 50 strokes machining

\begin{tabular}{|c|c|c|c|c|c|c|}
\hline \multicolumn{3}{|c|}{ Number of obs: 9} & \multicolumn{4}{|c|}{$R$-squared: 0.9951} \\
\hline \multicolumn{3}{|c|}{ Root MSE: 0.011465} & \multicolumn{4}{|c|}{ Adj $R$-squared: 0.9804} \\
\hline Source & Sum of squares & Degree of freedom & Mean square & $F$-value & Prob $>F$ & Percent contribution $(\%)$ \\
\hline Model & 0.053399 & 6 & 0.008900 & 67.71 & 0.0146 & \\
\hline$f z(\mathrm{~mm} /$ flute $)$ & 0.035730 & 2 & 0.017865 & 135.91 & 0.0073 & 66.58 \\
\hline$V(\mathrm{~m} / \mathrm{min})$ & 0.001050 & 2 & 0.000525 & 3.99 & 0.2003 & 1.96 \\
\hline$a(\mathrm{~mm})$ & 0.016620 & 2 & 0.008310 & 63.22 & 0.0156 & 30.97 \\
\hline Error & 0.000263 & 2 & 0.000131 & - & - & 0.49 \\
\hline Total & 0.053662 & 8 & 0.006708 & - & - & 100.00 \\
\hline
\end{tabular}




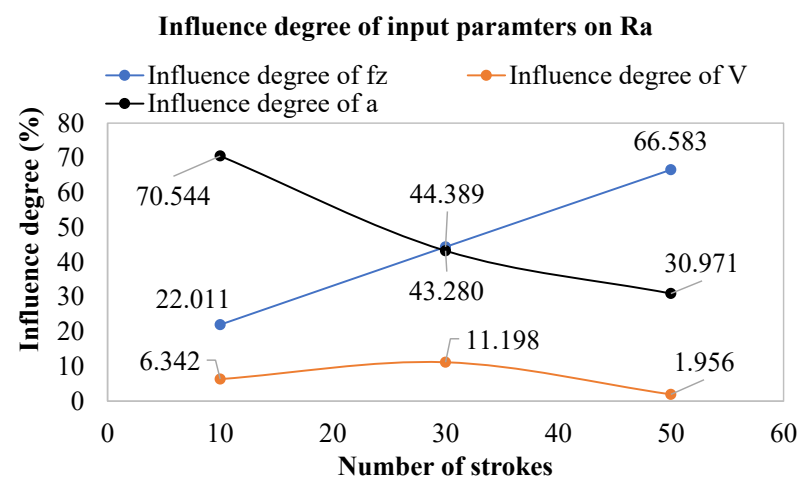

Fig. 8. Effect of cutting parameter on surface roughness

Surface roughness model after 10 strokes machining was presented by (4):

$$
\left\{\begin{array}{l}
R a(10 \text { strokes })=0.100+2.153 \cdot f z+0.000301 \cdot V-0.5053 \cdot a, \\
R^{2}=96.83 \%, R_{A j d}^{2}=94.93 \% .
\end{array}\right.
$$

Surface roughness model after 30 strokes machining was presented by (5):

$$
\left\{\begin{array}{l}
R a(30 \text { strokes })=-0.0617+3.078 \cdot f z+0.000385 \cdot V-0.3789 \cdot a, \\
R^{2}=97.67 \%, R_{A j d}^{2}=96.27 \% .
\end{array}\right.
$$

Surface roughness model after 50 strokes machining was presented by (6):

$$
\left\{\begin{array}{l}
R a(50 \text { strokes })=0.031+3.076 \cdot f z+0.000179 \cdot V-0.303 \cdot a, \\
R^{2}=90.24 \%, R_{A j d}^{2}=84.38 \% .
\end{array}\right.
$$

Using the experimental data, the relationship between a dependent variable and one or more independent variables can be created by regression analysis. For surface roughness in this study, a linear regression that was determined as the most suitable regression of surface roughness as given by (4)-(6) with $R^{2}$ values from $90.27 \%$ to $96.18 \%$. The surface roughness models were applied to predict the surface roughness and compare to the measured values of surface roughness. The surface roughness model was successfully verified by comparison of predicted and measured results of surface roughness as described in Fig. 9.

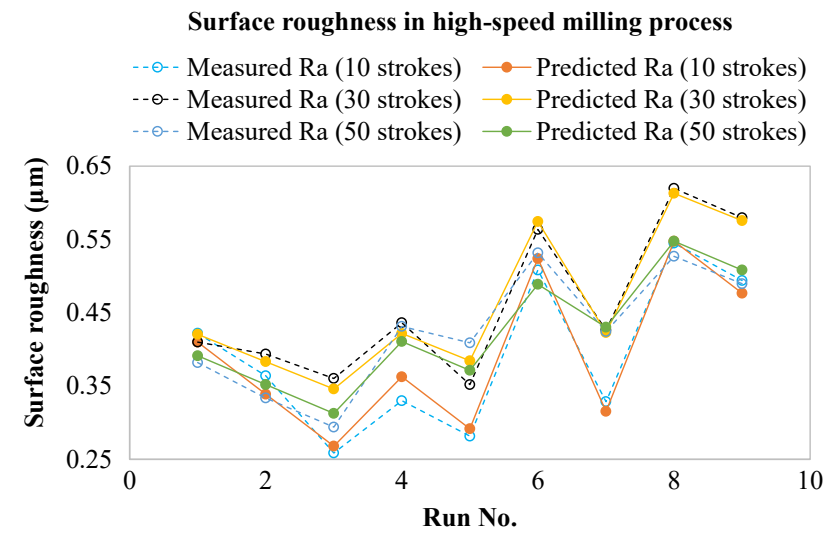

Fig. 9. Comparison of predicted and measured surface roughness

The compared results from this figure showed that in almost cases with the different of machining stroke numbers (10 machining strokes, 30 machining strokes, and 50 machining strokes), the predicted values surface roughness were quite close to values of the measured surface rough- 
ness. These results again proved that linear regression model can be used to model the surface roughness in high-speed face milling processes of aluminum alloy Al6061.

\section{3. Tendency of tool wear and surface roughness depending on milling strokes}

The tool wear that was changed depending on the number of machining strokes was described as in Fig. 10. This figure showed that, with the small number of machining strokes, the values of tool wear increased more strongly. After that when the number of machining strokes increased, the tool wear also increased within small values, after a machining with larger number of machining strokes, the tendency of tool wear continued increasing with more strongly.

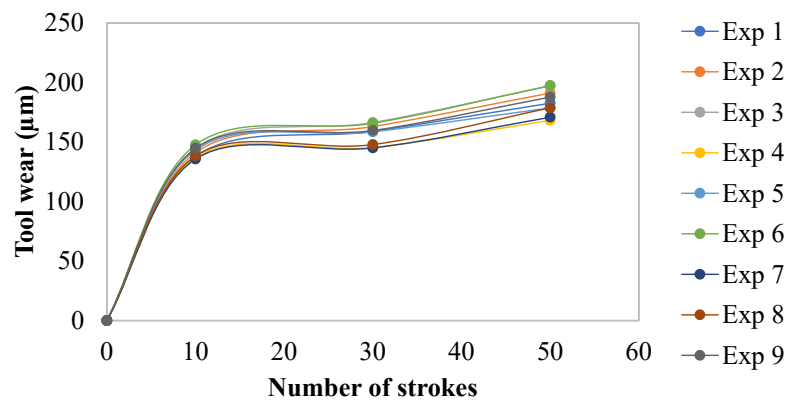

Fig. 10. Tool wear vs. number of machining strokes

The variation of the surface roughness depending on the number of machining strokes was investigate and illustrated in Fig. 11. This figure shows that the surface roughness tendency of all experiments was different with different experiments. The results from the Fig. 11 show that the surface roughness in machining tended to change, however, the change is not clear in different experiments. Therefore, it is necessary to conduct more in-depth studies to accurately evaluate the tendency of machining surface roughness according to the number of machining strokes (or machining time).

The investigation of relationship between tool wear and surface roughness is shown in Fig. 12.

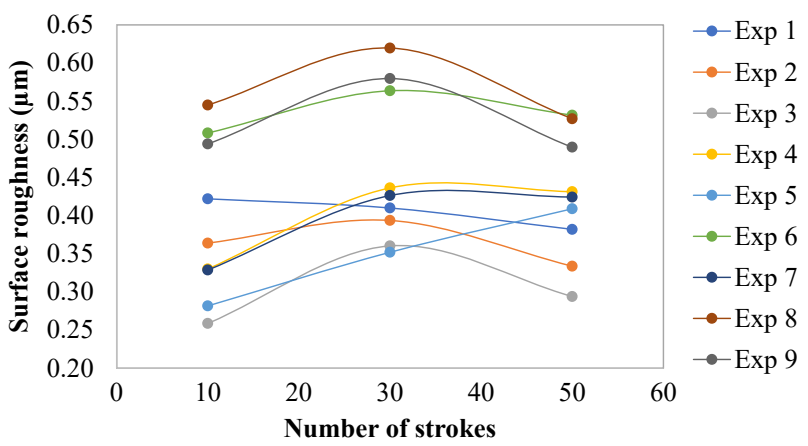

Fig. 11. Surface roughness vs. number of machining strokes

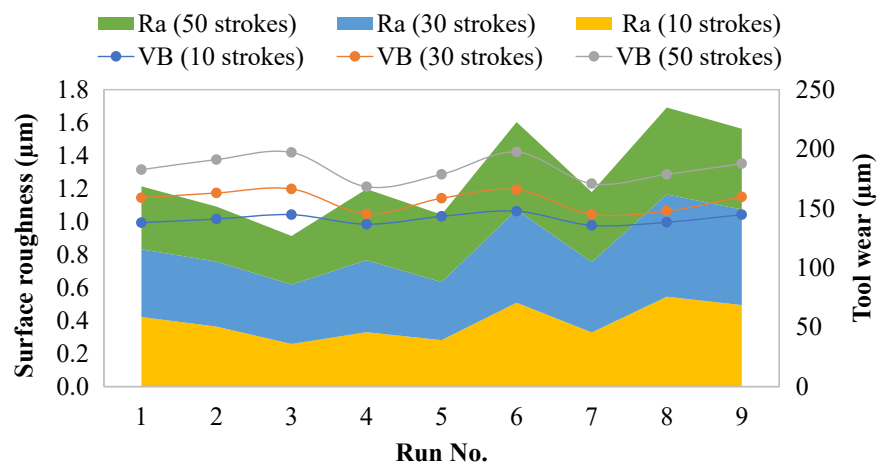

Fig. 12. Relationship between tool wear and surface roughness 
In almost cases, it seems that the tendency of the surface roughness was quite different to that one of tool wear in high-speed milling process. So, to evaluate the quality and effective of high-speed milling process, it is necessary to evaluate both surface roughness and tool wear.

\section{Discussion of experimental results}

The analyzed results for tool wear show that the cutting speed is the most influence parameter on the tool wear, followed by the influence of feed rate, whereas the depth of cut has a negligible effect on the tool wear as described in Table 5 and Fig. 6. This could be explained that tool wear is essentially caused by the reciprocal movement of the tool surface and workpiece surface. During cutting process, the reciprocating movement between the tool and the workpiece is characterized by the cutting speed and feed rate. Therefore, these two parameters have a significant effect on the tool wear. The depth of cut is not characteristic of the reciprocal movement of the tool and workpiece, so the depth of cut has little effect on the tool wear.

The analyzed results for surface roughness indicate that feed rate and cutting depth significantly influence on surface roughness, while cutting speed has negligible effect on surface roughness as described in Table 6 and Fig. 8. These results could be explained as follows: The machining surface undulating (surface roughness) is mainly formed from the geometrical interaction between the tool and the workpiece. In the cutting process, two of the parameters that characterize the geometrical interaction of the tool and workpiece are the feed rate and depth of cut. The cutting velocity that is mainly characteristic of the rate of the geometrical interaction forming. Therefore, the feed rate and cutting depth that are the parameters mainly affect on the surface roughness, while the cutting speed that will not be the parameter significantly affects the surface roughness.

The tendency of the change of tool wear depending on the number of machining strokes (Fig. 10) could be explained as follows: At the beginning time of the milling process, the new inserts that was used have many sharp edges, in milling process, the sharp edges will scratch the workpiece surface, making the tool wear increased more strongly. After a beginning period time of machining, due to the abrasion of the edges, these sharp edges do not scratch on the workpiece surface, making the tool wear tend to increase but these changes were quite mall. After a period of machining time, due to the increasing of the cutting forces, cutting temperature, the tool wear also increases more strongly.

The change rule of tool wear and surface roughness according to the number of machining strokes is not the same as shown in Fig. 12. These obtained results can be explained as follows: Unlike the conventional machining, during high-speed machining the factors affect very differently on the tool wear and surface roughness as analyzed in previous sections. Cutting speed is a parameter that greatly affects the tool wear, while the feed rate and depth of cut are the parameters that greatly affect on the surface roughness.

During the milling process of the aluminum alloy, the phenomenon of chips sticking on the tool causes the high wear and greatly affects on the quality of the machining surface. The highspeed milling method that is one of the suitable methods was applied to limit the above phenomena to improve the quality of the machining surface, reduce the tool wear, and increase the tool life. Therefore, the application of the experimental method to investigate the high-speed milling process of aluminum alloy is one of the highlights of this study.

This study just stopped at the experimental research and limited on the investigation of three basic input parameters of cutting process: cutting speed, feed rate, and cutting depth. While the effect of other parameters such as system vibrations, chatter, tool run-out, etc. on the cutting characteristics is significant during high-speed milling processes. However, this study has not mentioned the influence of these parameters on the tool wear and surface roughness.

In this study, the influence trend of the number of machining strokes on machining surface roughness is not clear as shown in Fig. 11. This study just stops at evaluating the influence of input parameters on output parameters and only with several input parameters. Therefore, in experimental research, it is necessary to change many values of the number of machining strokes, or with multiple values of machining time and with other cutting parameters to determine the exact rule of machining surface roughness. 
The studies that are performed to investigate the influence of many input parameters on the output parameters and to optimize the high-speed milling process of aluminum alloy to increase the machining productivity, surface quality, tool life, etc. will be the next research directions of this study.

\section{Conclusion}

This study that was conducted in high-speed face milling process of the aluminum alloy A16061. The conclusions of this study were drawn depending on the analyzed results as follows:

1. During the machining processing of aluminum alloy Al6061 with the carbide cutting insert, after different machining strokes (10 strokes, 30 strokes, and 50 strokes), the parameter that has most influence on the tool wear was the cutting speed (from $52.18 \%$, to $84.94 \%$ ). The parameter that has the second influence degree on the tool wear was the feed rate (from $9.73 \%$ to $37.18 \%$ ). The depth of cut has negligible effect on the tool wear (less than $5 \%$ ). The influence degree of the parameters on the tool wear varied with the number of machining strokes.

2. The feed rate and depth of cut were the most influence factors on the surface roughness (from $22.01 \%$, up to $66.58 \%$ for feed rate and (from $70.54 \%$ down to $30.97 \%$ for depth of cut). The cutting speed has negligible effect on the surface roughness (less than $11.20 \%$ ). The influence degree of the parameters on the surface roughness also varied with the number of machining strokes.

3. Linear regression that was determined as the most suitable regression of tool wear and surface roughness with the determination coefficients $\left(R^{2}\right)$ from $88.00 \%$ to $91.99 \%$ for tool wear, and from $90.24 \%$ to $97.67 \%$ for surface roughness. These regression models were successfully verified by comparison of predicted and measured results of tool wear and surface roughness.

4. The tool wear and surface roughness values that changed depending on the change of machining stroke number. The increasing tendency of tool wear is quite clear, in which the tendency to change surface roughness is not really clear.

The tool wear, surface roughness models, and their relationship that were found in this study can be used to improve the surface quality and the tool life in machining processes, etc. These will be the research direction in the future.

\section{Acknowledgements}

The authors appreciate the generous assistance from the Faculty of Mechanical Engineering, Hanoi University of Industry, Vietnam for the measurement system.

\section{References}

[1] Nguyen, N.-T., Tien, D. H., Trung, D. D. (2020). Multi-Objective Optimization when Surface Grinding the 3X13 Steel by Combining the General Reduced Gradient Algorithm and Harmonic Mean Method. Advances in Science, Technology and Engineering Systems Journal, 5 (5), 395-400. doi: https://doi.org/10.25046/aj050550

[2] Eckstein, M., Vrabel', M., Maňková, I. (2016). Tool Wear and Surface Roughness Evolution in Hole Making Process of Inconel 718. Materials Science Forum, 862, 11-17. doi: https://doi.org/10.4028/www.scientific.net/msf.862.11

[3] Gürgen, S., Tali, D., Kushan, M. C. (2019). An Investigation on Surface Roughness and Tool Wear in Turning Operation of Inconel 718. Journal of Aerospace Technology and Management. doi: https://doi.org/10.5028/jatm.v11.1030

[4] Behera, B. C., Alemayehu, H., Ghosh, S., Rao, P. V. (2017). A comparative study of recent lubri-coolant strategies for turning of Ni-based superalloy. Journal of Manufacturing Processes, 30, 541-552. doi: https://doi.org/10.1016/j.jmapro.2017.10.027

[5] Laghari, R. A., Li, J., Xie, Z., Wang, S. (2018). Modeling and Optimization of Tool Wear and Surface Roughness in Turning of Al/SiCp Using Response Surface Methodology. 3D Research, 9 (4). doi: https://doi.org/10.1007/s13319-018-0199-2

[6] Nguyen, N. T., Do, D. T. (2020). Modeling and Improvement of the Surface Roughness Model in Hole Turning Process $3 \times 13$ Stainless Steel by Using Johnson Transformation. International Journal of Mechanical and Production Engineering Research and Development (IJMPERD), 10 (3), 12097-12110. Available at: http://paper.researchbib.com/view/paper/260700

[7] Kilickap, E., Yardimeden, A., Çelik, Y. H. (2017). Mathematical Modelling and Optimization of Cutting Force, Tool Wear and Surface Roughness by Using Artificial Neural Network and Response Surface Methodology in Milling of Ti-6242S. Applied Sciences, 7 (10), 1064. doi: https://doi.org/10.3390/app7101064

[8] Li, Y., Zheng, G., Zhang, X., Cheng, X., Yang, X., Xu, R. (2019). Cutting force, tool wear and surface roughness in highspeed milling of high-strength steel with coated tools. Journal of Mechanical Science and Technology, 33 (11), $5393-5398$. doi: https://doi.org/10.1007/s12206-019-1033-3 
[9] Molla Ramezani, N., Rasti, A., Sadeghi, M. H., Jabbaripour, B., Rezaei Hajideh, M. (2016). Experimental study of tool wear and surface roughness on high speed helical milling in D2 steel. Modares Mechanical Engineering, 15 (13), 198-202. Available at: https://mme.modares.ac.ir/article-15-8858-en.html

[10] Nguyen, N.-T. (2020). A Study on Influence of Milling Types and Cutting Conditions on Surface Roughness in Milling of Aluminum Alloy Al6061-T6. Universal Journal of Mechanical Engineering, 8 (4), 183-190. doi: https://doi.org/10.13189/ ujme.2020.080403

[11] Nguyen, T., Park, K.-H., Wang, X., Olortegui-Yume, J., Wong, T., Schrock, D. et. al. (2015). The Genesis of Tool Wear in Machining. Volume 15: Advances in Multidisciplinary Engineering. doi: https://doi.org/10.1115/imece2015-52531

[12] Wang, R., Wang, B., Barber, G., Gu, J., Schall, J. D. (2019). Models for Prediction of Surface Roughness in a Face Milling Process Using Triangular Inserts. Lubricants, 7 (1), 9. doi: https://doi.org/10.3390/lubricants7010009

[13] Coppini, N. L., Diniz, A. E., Lacerda, F. S., Bonandi, M., Baptista, E. A. (2018). Internal turning of sintered carbide parts: tool wear and surface roughness evaluation. Journal of the Brazilian Society of Mechanical Sciences and Engineering, 40 (4). doi: https://doi.org/10.1007/s40430-018-1139-z

[14] Hoang, D. T., Nguyen, N.-T., Tran, Q. D., Nguyen, T. V. (2019). Cutting Forces and Surface Roughness in Face-Milling of SKD61 Hard Steel. Strojniški Vestnik - Journal of Mechanical Engineering, 65 (6), 375-385. doi: https://doi.org/10.5545/ sv-jme.2019.6057

[15] Jeyakumar, S., Marimuthu, K., Ramachandran, T. (2013). Prediction of cutting force, tool wear and surface roughness of Al6061/SiC composite for end milling operations using RSM. Journal of Mechanical Science and Technology, 27 (9), 2813-2822. doi: https://doi.org/10.1007/s12206-013-0729-z

[16] Kundor, N. F., Awang, N. W., Berahim, N. (2016). Tool Wear and Surface Roughness in Machining AISI D2 Tool Steel. Indian Journal of Science and Technology, 9 (18). doi: https://oi.org/10.17485/ijst/2016/v9i18/88731

[17] Said, M. S., Ghani, J. A., Che Haron, C. H., Yusoff, S., Selamat, M. A., Othman, R. (2013). Tool Wear and Surface Roughness when Machining A1Si/AlN Metal Matrix Composite Using Uncoated Carbide Cutting Tool. Materials Science Forum, 773-774, 409-413. doi: https://doi.org/10.4028/www.scientific.net/msf.773-774.409

[18] Ali, S. M., Dhar, N. R. (2010). Modeling of tool wear and surface roughness under MQL condition-a neural approach. Canadian Journal on Artificial Intelligence, Machine Learning \& Pattern Recognition, 1 (2), 7-25.

[19] Junaid Mir, M., Wani, M. F. (2018). Modelling and analysis of tool wear and surface roughness in hard turning of AISI D2 steel using response surface methodology. International Journal of Industrial Engineering Computations, 9, 63-74. doi: https://doi.org/ $10.5267 / j . j i j i e c .2017 .4 .004$

[20] Trang, L. N., Tran, X.-T., Hai, N. T., Nguyen, N.-T. (2020). An investigation and analysis of surface roughness and tool wear in dry pocket milling of Aluminum alloy A17075. International Journal of Mechanical and Production Engineering Research and Development (IJMPERD), 10 (2), 1307-1320. Available at: http://www.tjprc.org/publishpapers/2-67-1587533979-126IJMPERDAPR2020126.pdf

[21] Asiltürk, İ., Akkuş, H. (2011). Determining the effect of cutting parameters on surface roughness in hard turning using the Taguchi method. Measurement, 44 (9), 1697-1704. doi: https://doi.org/10.1016/j.measurement.2011.07.003

[22] Suresh, R., Basavarajappa, S., Samuel, G. L. (2012). Some studies on hard turning of AISI 4340 steel using multilayer coated carbide tool. Measurement, 45 (7), 1872-1884. doi: https://doi.org/10.1016/j.measurement.2012.03.024

[23] Yıldırım, Ç. V., Kıvak, T., Erzincanll, F. (2019). Tool wear and surface roughness analysis in milling with ceramic tools of Waspaloy: a comparison of machining performance with different cooling methods. Journal of the Brazilian Society of Mechanical Sciences and Engineering, 41 (2). doi: https://doi.org/10.1007/s40430-019-1582-5

[24] Lumley, R. (Ed.) (2011). Fundamentals of aluminium metallurgy: production, processing and applications. Elsevier. doi: https:// doi.org/10.1533/9780857090256

[25] Lezanski, P., Shaw, M. C. (1990). Tool Face Temperatures in High Speed Milling. Journal of Engineering for Industry, 112 (2), 132-135. doi: https://doi.org/10.1115/1.2899555

Received date 23.02.2021

(C) The Author(s) 2021

Accepted date 25.04.2021

Published date 31.05.2021

This is an open access article under the Creative Commons CC BY license

How to cite: Nguyen, N.-T., Tien, D. H., Tung, N. T., Luan, N. D. (2021). Analysis of tool wear and surface roughness in highspeed milling process of aluminum alloy Al6061. EUREKA: Physics and Engineering, 3, 71-84. doi: https://doi.org/10.21303/ 2461-4262.2021.001824 